\title{
Manufacturing $\mathrm{ZrB}_{2}-\mathrm{SiC}-\mathrm{TaC}$ Composite: Potential Application for Aircraft Wing Assessed by Frequency Analysis through Finite Element Model
}

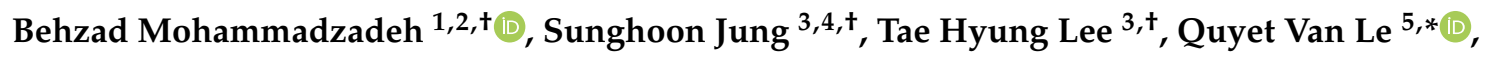 \\ Joo Hwan Cha ${ }^{6}$, Ho Won Jang ${ }^{3} \mathbb{D}$, Sea-Hoon Lee ${ }^{7, *}$, Junsuk Kang ${ }^{1,2, * \mathbb{D}}$ and \\ Mohammadreza Shokouhimehr ${ }^{3, * \mathbb{D}}$ \\ 1 Department of Landscape Architecture and Rural Systems Engineering, Seoul National University, Seoul \\ 08826, Korea; Behzad3049@snu.ac.kr \\ 2 Research Institute of Agriculture and Life Sciences, Seoul National University, Seoul 08826, Korea \\ 3 Department of Materials Science and Engineering, Research Institute of Advanced Materials, Seoul National \\ University, Seoul 08826, Korea; gns84@snu.ac.kr (S.J.); sunshinety@snu.ac.kr (T.H.L.); \\ hwjang@snu.ac.kr (H.W.J.) \\ 4 Advanced Nano Surface Department, Surface Technology Division, Korea Institute of Materials Science, \\ Changwon 51508, Korea \\ 5 Institute of Research and Development, Duy Tan University, Da Nang 550000, Vietnam \\ 6 Innovative Enterprise Cooperation Center, Korea Institute of Science \& Technology, Hwarangro 14-gil, \\ Seongbuk-gu, Seoul 02792, Korea; jhcha@kist.re.kr \\ 7 Division of Powder/Ceramics Research, Korea Institute of Materials Science, Changwon 51508, Korea \\ * Correspondence: levanquyet@dtu.edu.vn (Q.V.L.); seahoon1@kims.re.kr (S.-H.L.); Junkang@snu.ac.kr (J.K.); \\ mrsh2@snu.ac.kr (M.S.) \\ + These authors contributed equally in this work.
}

Received: 6 April 2020; Accepted: 8 May 2020; Published: 12 May 2020

\begin{abstract}
This study presents a new ultra-high temperature composite fabricated by using zirconium diboride $\left(\mathrm{ZrB}_{2}\right)$, silicon carbide $(\mathrm{SiC})$, and tantalum carbide $(\mathrm{TaC})$ with the volume ratios of $70 \%, 20 \%$, and $10 \%$, respectively. To attain this novel composite, an advanced processing technique of spark plasma sintering (SPS) was applied to produce $\mathrm{ZrB}_{2}-\mathrm{SiC}-\mathrm{TaC}$. The SPS manufacturing process was achieved under pressure of $30 \mathrm{MPa}$, at $2000{ }^{\circ} \mathrm{C}$ for $5 \mathrm{~min}$. The micro/nanostructure and mechanical characteristics of the composite were clarified using X-ray diffraction (XRD), field-emission scanning electron microscopy (FESEM), and nano-indentation. For further investigations of the product and its characteristics, $\mathrm{X}$-ray fluorescence $(\mathrm{XRF})$ analysis and X-ray photoelectron spectroscopy (XPS) were undertaken, and the main constituting components were provided. The composite was densified to obtain a fully-dense ternary; the oxide pollutions were wiped out. The mean values of 23,356; $403.5 \mathrm{GPa}$; and $3100{ }^{\circ} \mathrm{C}$ were obtained for the rigidity, elastic modulus, and thermal resistance of the $\mathrm{ZrB}_{2}-\mathrm{SiC}-\mathrm{TaC}$ interface, respectively. To explore the practical application of the composite, the natural frequency of an aircraft wing considering three cases of materials: (i) with a leading edge made of $\mathrm{ZrB}_{2}-\mathrm{SiC}-\mathrm{TaC}$; (ii) the whole wing made of $\mathrm{ZrB}_{2}-\mathrm{SiC}-\mathrm{TaC}$; and (iii) the whole wing made of aluminum 2024-T3 were investigated employing a numerical finite element model (FEM) tool ABAQUS and compared with that of a wing of traditional materials. The precision of the method was verified by performing static analysis to obtain the responses of the wing including total deformation, equivalent stress, and strain. A comparison study of the results of this study and published literature clarified the validity of the FEM analysis of the current research. The composite produced in this study significantly can improve the vibrational responses and structural behavior of the aircraft's wings.
\end{abstract}


Keywords: ultra-high temperature ceramic; spark plasma sintering; nano-indentation; composite; vibration analysis; FEM analysis

\section{Introduction}

Ultra-high temperature ceramics (UHTCs) are refractory materials presenting outstanding mechanical properties at elevated temperatures beyond $2000{ }^{\circ} \mathrm{C}$ [1-3]. They have been used for possible thermal protection systems, coating of objects exposed to high temperatures, and biomedical applications [4-7]. A few natural elements exist having ultra-high melting points over $3000{ }^{\circ} \mathrm{C}$ such as carbon, rhenium, osmium, tungsten, and tantalum [8-10]. Also, limited chemical compounds having high-temperature resistance have been achieved and utilized for various applications, e.g., thorium dioxide $\left(\mathrm{ThO}_{2}\right)$, tantalum diboride $\left(\mathrm{TaB}_{2}\right)$, zirconium diboride $\left(\mathrm{ZrB}_{2}\right)$, tantalum carbide $(\mathrm{TaC})$, hafnium carbide ( $\mathrm{HfC})$, zirconium carbide $(\mathrm{ZrC})$, titanium carbide ( $\mathrm{TiC})$, etc. [11-14].

The huge demand for high-temperature resistant materials for industries, especially aerospace, has motivated the Air Force Materials Laboratory to develop a new class of materials tolerating the harsh environment of proposed hypersonic vehicles such as Dyna-soar and the Space Shuttle at Man Labs Incorporated [15]. Assessment of the refractory properties of binary ceramics showed that the metal borides, carbides, and nitrides possessed the significant thermal conductivity and oxidation resistance as well as appropriate mechanical strength in the case of using small grain size. Among the aforementioned materials, $\mathrm{ZrB}_{2}$ and $\mathrm{HfB}_{2}$ in composites comprising $20 \%$ volume $\mathrm{SiC}$ have presented the most efficient and practical applications. A significant number of research studies reported in the literature dealt with improving the performance of $\mathrm{ZrB}_{2}$ and $\mathrm{HfB}_{2}$ despite having numerous works that have been undertaken to characterize the nitrides, oxides, carbides, etc. [16-20]. There are several documented studies presenting the diborides utilization for high thermal conductivity and low melting points. These unique properties of such ceramics provide significant thermal resistance making them ideal candidates for elevated-thermal applications [21-23]. Among the UHTCs, the Zr-based diborides have been developed with the aim of tolerating ambient loads and elevated temperatures which can be experienced by leading vehicle edges in sustained hypersonic flight [24,25]. The surfaces of aircraft vehicles are exposed to drastically elevated temperatures and high flow-rate oxidation. It has been documented that $\mathrm{ZrB}_{2}$-based UHTCs can retain shape under high-temperature surroundings because of their significant oxidation resistance and high melting point [26-28].

$\mathrm{ZrB}_{2}$ has been considered one of the most promising thermal protection materials and employed for a wide range of structural and industrial applications [29-31]. From the results given in the literature, it has been figured out that $\mathrm{ZrB}_{2}$-based UHTCs possess an outstanding oxidation resistance, rigidity, and fracture toughness. It was observed that the oxidation resistance of $\mathrm{ZrB}_{2}-\mathrm{SiC}$ composite was supreme in the air up to $1500^{\circ} \mathrm{C}$ boosting the strength by healing the surface flaws [32,33]. The significant oxidation resistance of $\mathrm{ZrB}_{2}-\mathrm{SiC}$ beyond $1800^{\circ} \mathrm{C}$ has been also reported presenting outstanding integrity of the underlying microstructure under specific situations $[34,35]$. Furthermore, huge efforts have been assigned to the assessment of high-temperature mechanical properties of $\mathrm{ZrB}_{2}$-based ceramics, particularly by incorporating various additives. In this regard, several studies have been reported on the investigation of the flexure strength of $\mathrm{ZrB}_{2}$-based ceramics at high temperatures by employing the three-point bending test. The results showed that the flexure strength, stiffness, thermal, and corrosion resistance were relatively decreased with increasing the temperature [36-38]. Among various additives included to UHTCs for improving their properties, $\mathrm{TaC}$ is unique because of its high melting point $\left(\sim 3880^{\circ} \mathrm{C}\right)$ which is among the highest for binary compounds. Furthermore, TaC has a microhardness of $1600-2000 \mathrm{~kg} / \mathrm{mm}^{2}$, and an elastic modulus of $285 \mathrm{GPa}$.

This study focuses on the production of a new type of UHTCs having superior characteristics to the existing conventional counterparts and newly manufactured $\mathrm{ZrB}_{2}$-based materials [39-49]. Based on the investigations through the characteristics of different additives, this study employed 
$\mathrm{TaC}$ nanopowder to enhance the mechanical properties of $\mathrm{ZrB}_{2}-\mathrm{SiC}$ for industrial and structural applications. Thereafter, to visualize the practical application of the presented manufactured composite, it was adopted for the aerospace applications. For this aim, the finite element (FE) method which has been frequently used as an outstanding tool for a wide range of applications such as modeling materials, and structural and mechanical components, vibration analysis, buckling analysis, crack propagation, and blast analysis of structures and materials, was taken into account [50-60]. In this regard, the FE package ABAQUS was adopted to evaluate the natural frequencies of an aircraft wing of aluminum 2024-T3 and the leading edge made of the $\mathrm{ZrB}_{2}-\mathrm{SiC}-\mathrm{TaC}$.

\section{Experimental Setup}

\subsection{The Manufacturing Process of $\mathrm{ZrB}_{2}-\mathrm{SiC}-\mathrm{TaC}$}

To manufacture the $\mathrm{ZrB}_{2}-\mathrm{SiC}-\mathrm{TaC}$ composite, $\mathrm{ZrB}_{2}, \mathrm{SiC}$, and $\mathrm{TaC}$ were mixed in the form of powder with the volume fractions of $70 \%, 20 \%$, and $10 \%$, respectively. The purity of $\mathrm{ZrB}_{2}$ was greater than $99.8 \%$ with the particle size smaller than $2 \mu \mathrm{m}$. SiC had a particle size of $<3 \mu \mathrm{m}$ with a purity of $99.2 \%$, while the $\mathrm{TaC}$ powder size was smaller than $100 \mathrm{~nm}$ having a purity of $99.5 \%$. The mixing of the starting materials was carried out inside an ultrasonic bath with ethanol lasting for $80 \mathrm{~min}$. The admixture was completely dried using a magnetic hot plate and a stove. When the mixture was thoroughly loaded in the mold, the sintering process was carried out by spark plasma sintering (SPS) subjected to $2000{ }^{\circ} \mathrm{C}$ under $30 \mathrm{MPa}$ pressure for $5 \mathrm{~min}$. The obtained pallet with a thickness of $6 \mathrm{~mm}$ and a diameter of $2.4 \mathrm{~mm}$ was unfolded by grinding using a diamond grinding disk and eliminating its graphite foil cover.

\subsection{Analysis and Characterization}

To characterize the crystal structure of the prepared composite, a high-resolution X-ray diffractometer (XRD) was performed on a Bruker D8 Advance instrument (Bruker, Billerica, MA, USA). To obtain the mechanical characteristics of the composite the instrumented nano-indentation test was adopted by employing the Berkovich indenter. $\mathrm{ZrB}_{2}-\mathrm{SiC}-\mathrm{TaC}$ was investigated by the Oliver-Pharr method to reveal its mechanical and thermal properties such as modulus of elasticity (E), Poisson's ratio $(v)$, rigidity, and fracture toughness, and the load-displacement relationship. For this aim, XRD, and nano-indentation were utilized. Field-emission scanning electron microscopy (FESEM) images were attained using a SUPRA 55VP and Sigma Carl Zeiss (Zeiss, Oberkochen, Germany) instrument equipped with energy-dispersive X-ray spectroscopy (EDS). X-ray photoelectron spectroscopy (XPS) was carried out using an Al K $\alpha$ source (Sigma probe, VG Scientifics). The field emission-electron probe microanalyzer (FE-EPMA) was acquired using a JXA-8530F, JEOL (Tokyo, Japan). X-ray fluorescence (XRF) spectroscopy was achieved by an XRF-1800, Shimadzu (Kyoto, Japan).

\section{Potential Applications and Computational Model}

The prominent requirements of mechanical, thermal, and corrosion properties for the materials used for aerospace applications limits the choice of materials to carbides, borides, nitrides of the transition metals, etc. Among the available materials, $\mathrm{TaC}$ is unique because of its high melting point over $3000{ }^{\circ} \mathrm{C}$. Moreover, the TaC-based composites provide enhanced mechanical characteristics compared with other UHTCs. The composite of this study, $\mathrm{ZrB}_{2}-\mathrm{SiC}-\mathrm{TaC}$, can be an appropriate alternative for current commercial materials for long-term aerospace applications. The components of the leading edge and nose cap of aircraft are exposed to temperatures higher than $2000^{\circ} \mathrm{C}$ and subjected to complex stresses. The illustration of the possible applications of the materials of this research in aircraft wings is provided in Figure 1a. 

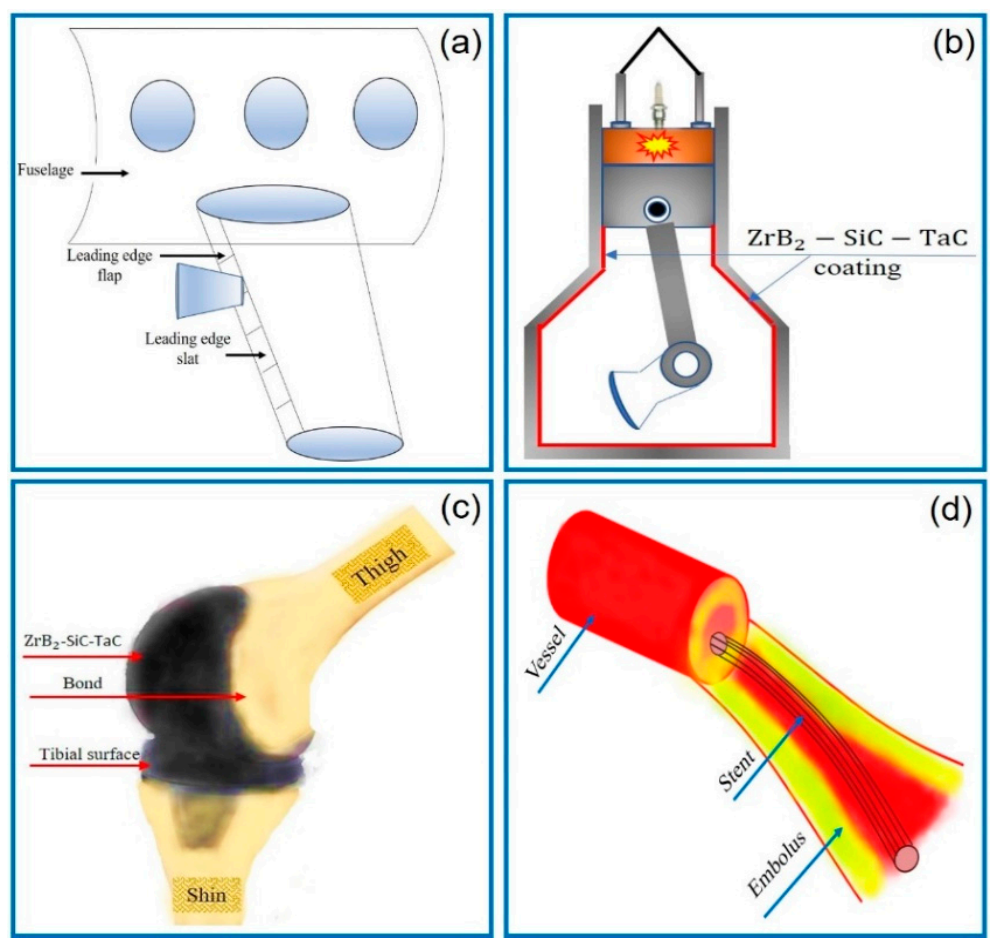

Figure 1. Potential applications of $\mathrm{ZrB}_{2}-\mathrm{SiC}-\mathrm{TaC}$ for (a) aerospace, (b) combustion cylinder of the car engine, (c) artificial knee joint, and (d) stent.

Furthermore, the refractory property and high toughness of $\mathrm{ZrB}_{2}-\mathrm{SiC}-\mathrm{TaC}$ enable it to be used for car engines and brakes, nuclear reactors, and coating on wooden structures. It can also be used for electric and electronic devices because $\mathrm{ZrB}_{2}$ acts as an electrical conductor, while $\mathrm{SiC}$ functions as an electrical ceramic. Figure $1 \mathrm{~b}$ illustrates the potential application of this ceramic for the car industry used as an internal coating of the combustion chamber. Due to the high fracture toughness, corrosion, and oxidation resistance of the presented ceramic, it can also be utilized for biomedical applications, e.g., knee joints (Figure 1c). Furthermore, it can be applied for stent fabrication to keep the arteries passageway open. Figure $1 \mathrm{~d}$ shows the possible biomedical applications for the $\mathrm{ZrB}_{2}-\mathrm{SiC}-\mathrm{TaC}$ in artificial knee replacement and stent used to open clogged arteries.

To examine the practical applications of $\mathrm{ZrB}_{2}-\mathrm{SiC}-\mathrm{TaC}$, this study adopted the commercially available finite element package ABAQUS to investigate the natural frequencies of the aircraft wing with a leading edge made of the ceramic. The solid elements were adopted for the geometrical modeling of the wing. There are two models in terms of the materials: (i) the case that the aluminum 2024-T3 was specified to the global body of the wing while the composite of this study was allocated to the leading-edge; and (ii) the wing made totally with aluminum 2024-T3. It is worth noting that in the case of having a wing made of both materials, the volume fraction of the $\mathrm{ZrB}_{2}-\mathrm{SiC}-\mathrm{TaC}$ used for leading-edge is $\sim 18 \%$, and for aluminum used in the rest of the wing is $\sim 72 \%$. The mechanical properties of the materials used for the wing are provided in Table 1.

There are two commonly used elements for meshing 3D models: the brick element and the tetrahedron element. It has been documented that brick elements can show better performance compared with the tetrahedron. However, for the cases of complex geometries, the probability of geometry degradation exists when meshing the model with brick elements. In addition, the number of nodes of brick elements is higher than the number of elements which significantly increases the computational time. Re-meshing of the brick elements is difficult and hence may not be suitable for large deformation problems. Therefore, the tetrahedron element, the 10-node quadratic tetrahedron (C3D10), was adopted for the numerical model of this study. To find the appropriate mesh size, the convergence study was performed and the corresponding graph is illustrated in Figure 2a. 
Table 1. Rigidity and elastic modulus of each phase.

\begin{tabular}{ccc}
\hline Mechanical Property & Material & Value \\
\hline \multirow{2}{*}{ Elastic modulus $(\mathrm{GPa})$} & $\mathrm{ZrB}_{2}-\mathrm{SiC}-\mathrm{TaC}$ & 403.5 \\
& Aluminum 2024-T3 & 73.1 \\
\hline \multirow{2}{*}{ Poisson's ratio } & $\mathrm{ZrB}_{2}-\mathrm{SiC}-\mathrm{TaC}$ & 0.29 \\
& $\mathrm{Aluminum} \mathrm{2024-T3}$ & 0.33 \\
\hline \multirow{2}{*}{ Density $\left(\mathrm{kg} / \mathrm{m}^{3}\right)$} & $\mathrm{ZrB}_{2}-\mathrm{SiC}-\mathrm{TaC}$ & 3000 \\
& Aluminum 2024-T3 & 2780 \\
\hline
\end{tabular}
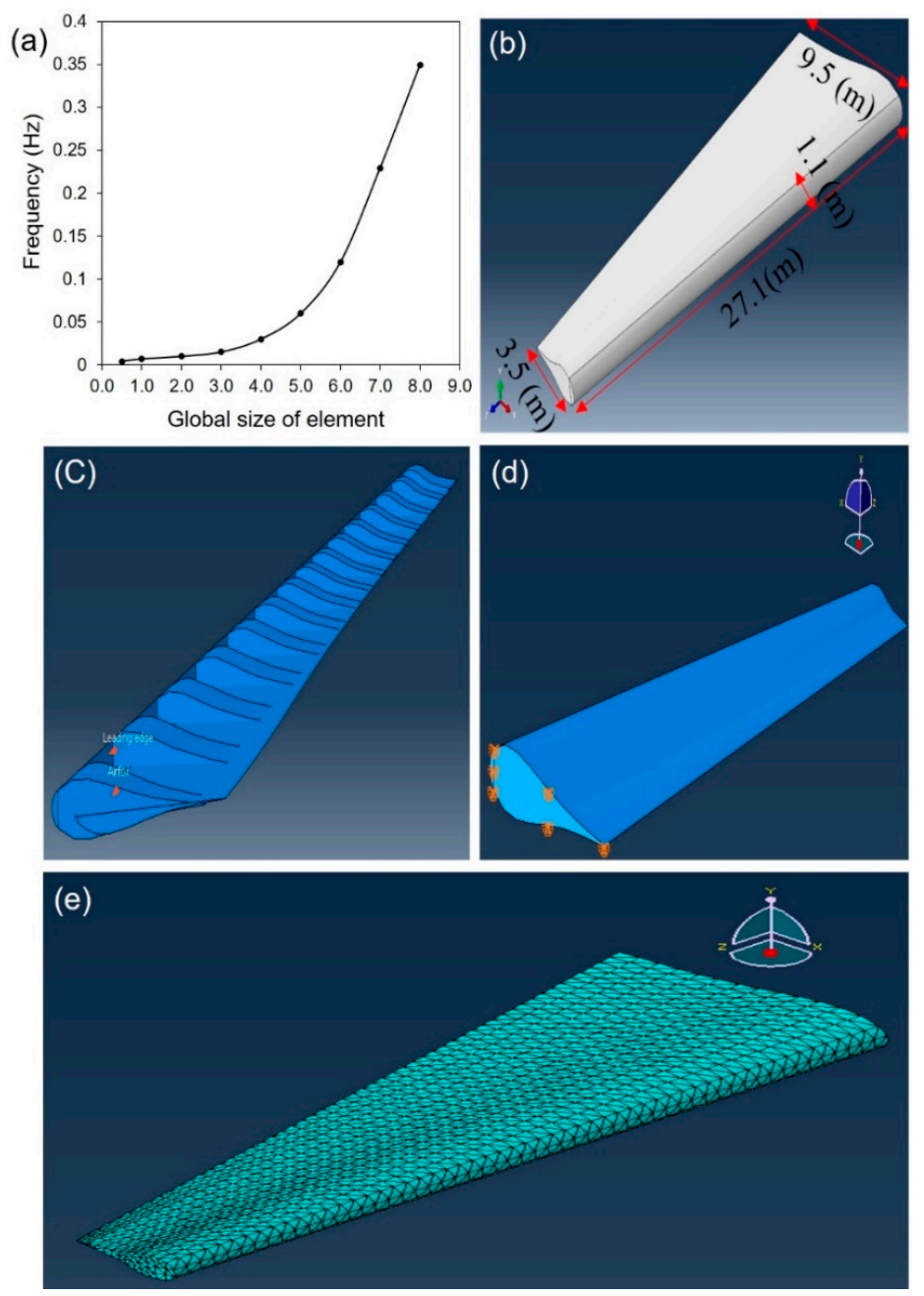

Figure 2. The mesh size evaluation and model of the aircraft wing in ABAQUS: (a) convergence study evaluating the appropriate mesh size for the wing, (b) wing dimensions, (c) internal view of wing showing the inside construction, and (d) clamped boundary conditions applied on the wing end, (e) meshed model.

It can be seen from Figure 2a that as the size of elements increases the convergence of the results decreases such that after the size of 3.0, the rate of divergence exponentially increases. In this study, to achieve reliable results, the global size of 0.5 was adopted for the mesh size. The geometry of the wing model in ABAQUS is illustrated in Figure $2 b$ while the open-view of the wing showing the airfoils inside the wing is provided in Figure 2c. The boundary conditions shown on the wing end which are connected to aircraft fuselage is provided in Figure 2d, and the meshed model is given in Figure 2e. 


\section{Results}

\subsection{Characterization of $\mathrm{ZrB}{ }_{2}-\mathrm{SiC}-\mathrm{TaC}$}

To provide a better insight into the crystal structure and determine the characteristics of $\mathrm{ZrB}_{2}-\mathrm{SiC}-\mathrm{TaC}$, several methods were employed, namely nano-indentation, XRD, XRF, FE-EPMA, and FESEM. The XRD pattern of the prepared ceramic is shown in Figure 3.

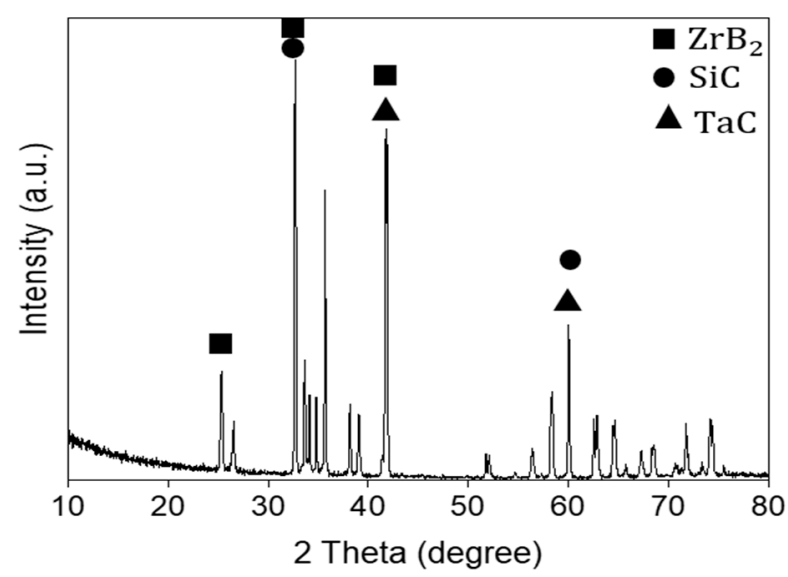

Figure 3. X-ray diffraction (XRD) pattern of $\mathrm{ZrB}_{2}-\mathrm{SiC}-\mathrm{TaC}$.

XPS analysis of the elements existing in ceramic and the composition of $\mathrm{ZrB}_{2}-\mathrm{SiC}-\mathrm{TaC}$ is illustrated in Figure 4.
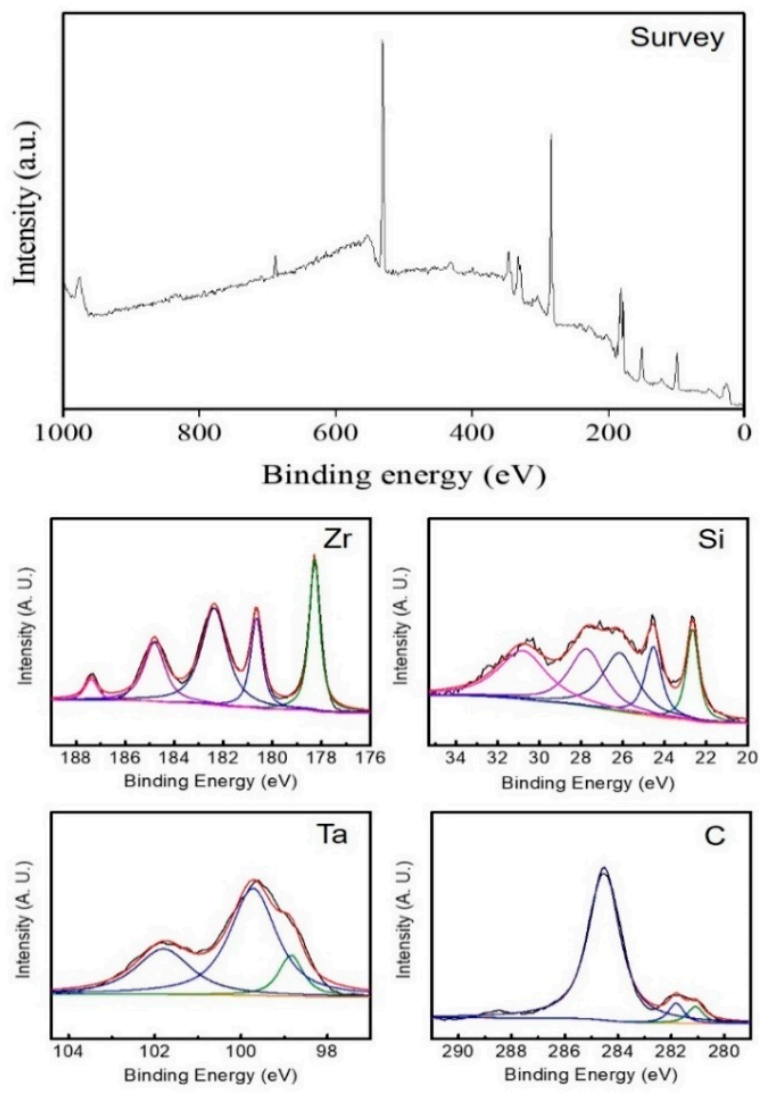

Figure 4. X-ray photoelectron spectroscopy (XPS) of $\mathrm{ZrB}_{2}-\mathrm{SiC}-\mathrm{TaC}$ and its constituent compounds. 
The graph showing the XRF of the composite of this study is given in Figure 5 while the nano-indentation of $\mathrm{ZrB}_{2}-\mathrm{SiC}-\mathrm{TaC}$ showing the load-displacement relationship of this composite is provided in Figure 6.

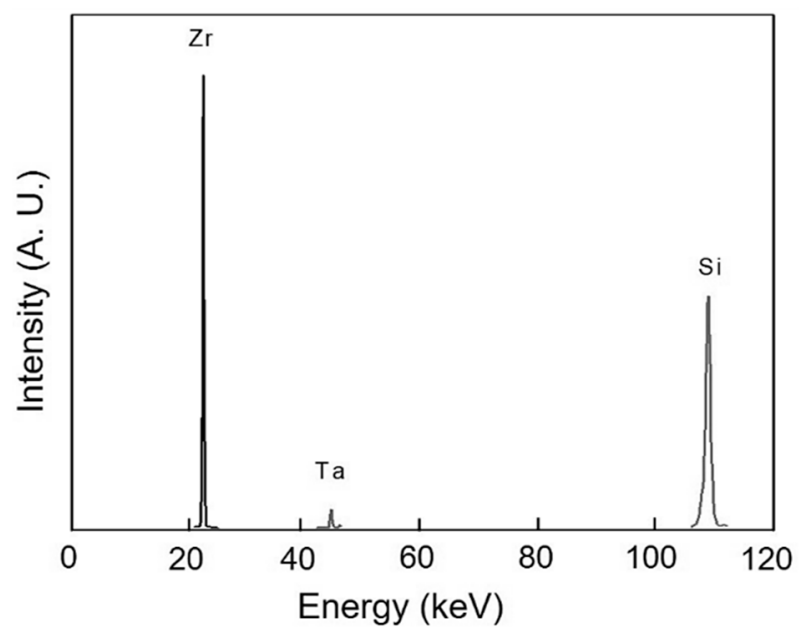

Figure 5. X-ray fluorescence (XRF) spectroscopy of $\mathrm{ZrB}_{2}-\mathrm{SiC}-\mathrm{TaC}$.

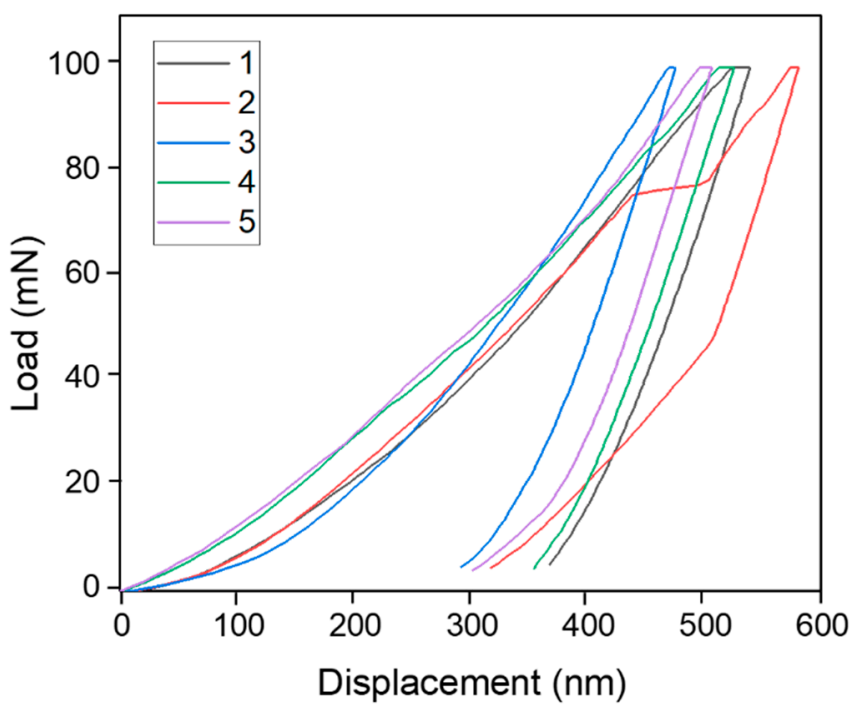

Figure 6. Nano-indentation of $\mathrm{ZrB}_{2}-\mathrm{SiC}-\mathrm{TaC}$.

Furthermore, the non-destructive analytical technique of $\mathrm{XRF}$ was used to determine the elemental composition of $\mathrm{ZrB}_{2}-\mathrm{SiC}-\mathrm{TaC}$. The characteristics of the $\mathrm{ZrB}_{2}-\mathrm{SiC}-\mathrm{TaC}$ are provided in Table 2.

Table 2. Mechanical and thermal properties of the material interface.

\begin{tabular}{ccccc}
\hline Mechanical Property & Phase & Min & Max & Mean \\
\hline Rigidity $(\mathrm{GPa})$ & $\mathrm{ZrB}_{2}-\mathrm{SiC}-\mathrm{TaC}$ Interface & 16218 & 26125 & 23356 \\
Elastic modulus $(\mathrm{GPa})$ & $\mathrm{ZrB}_{2}-\mathrm{SiC}-\mathrm{TaC}$ Interface & 359.4 & 460.1 & 403.5 \\
Thermal resistance $\left({ }^{\circ} \mathrm{C}\right)$ & $\mathrm{ZrB}_{2}-\mathrm{SiC}-\mathrm{TaC}$ Interface & 3000 & 3200 & 3100 \\
\hline
\end{tabular}

Table 2 shows that $\mathrm{ZrB}_{2}-\mathrm{SiC}-\mathrm{TaC}$ has very high rigidity, elastic modulus, and thermal resistance. These outstanding properties together with its high thermal and oxidation resistance expands its utilization for industrial and structural applications. Figure 7 shows the FESEM images of $\mathrm{ZrB}_{2}-\mathrm{SiC}-\mathrm{TaC}$ composite. 


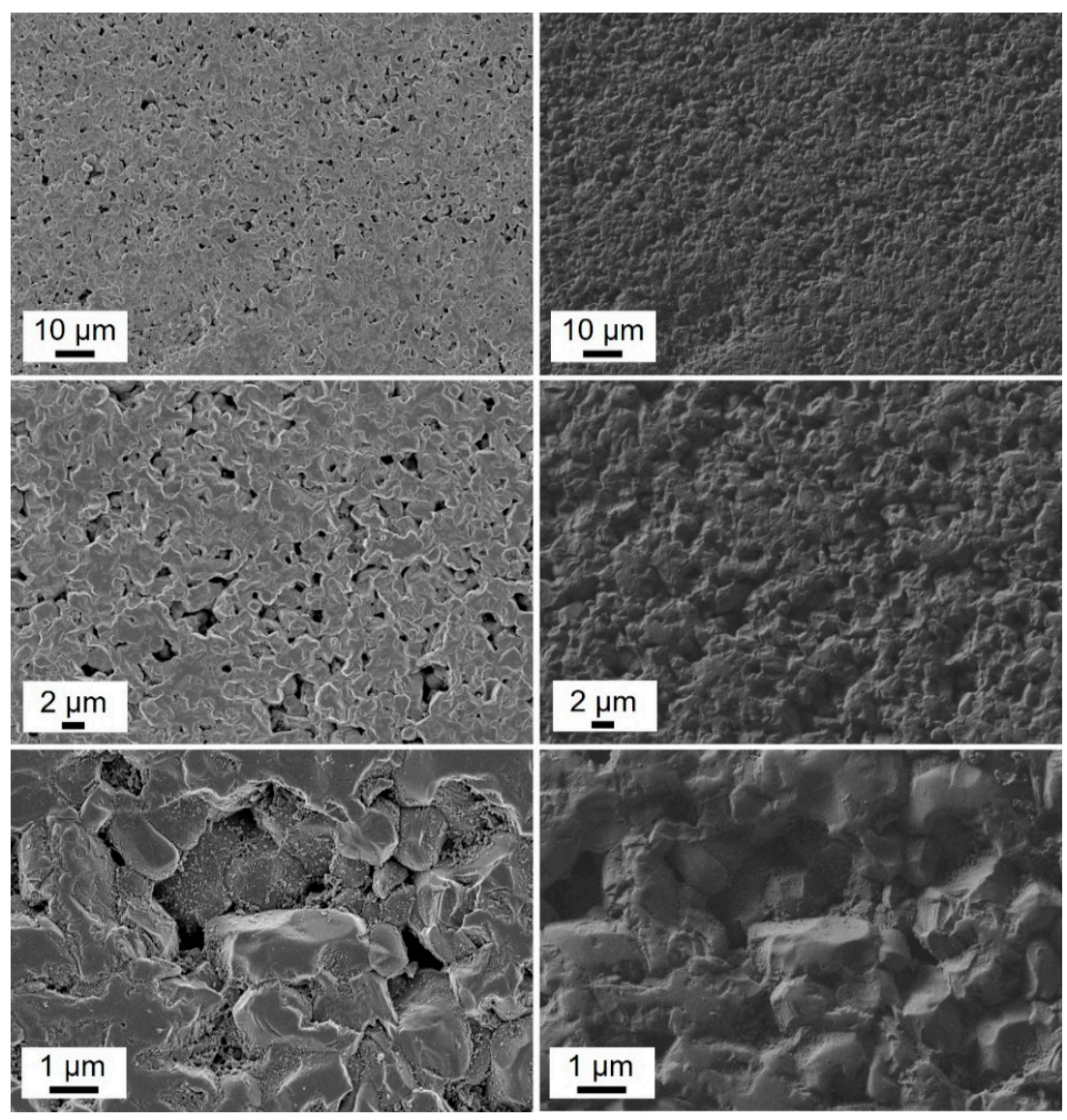

Figure 7. Different magnification of field-emission scanning electron microscopy (FESEM, left), and corresponding secondary electron detector (right) images of $\mathrm{ZrB}_{2}-\mathrm{SiC}-\mathrm{TaC}$.

The EDS elemental map of the composite presenting zirconium, boron, carbon, silicon, and tantalum is provided in Figure 8.

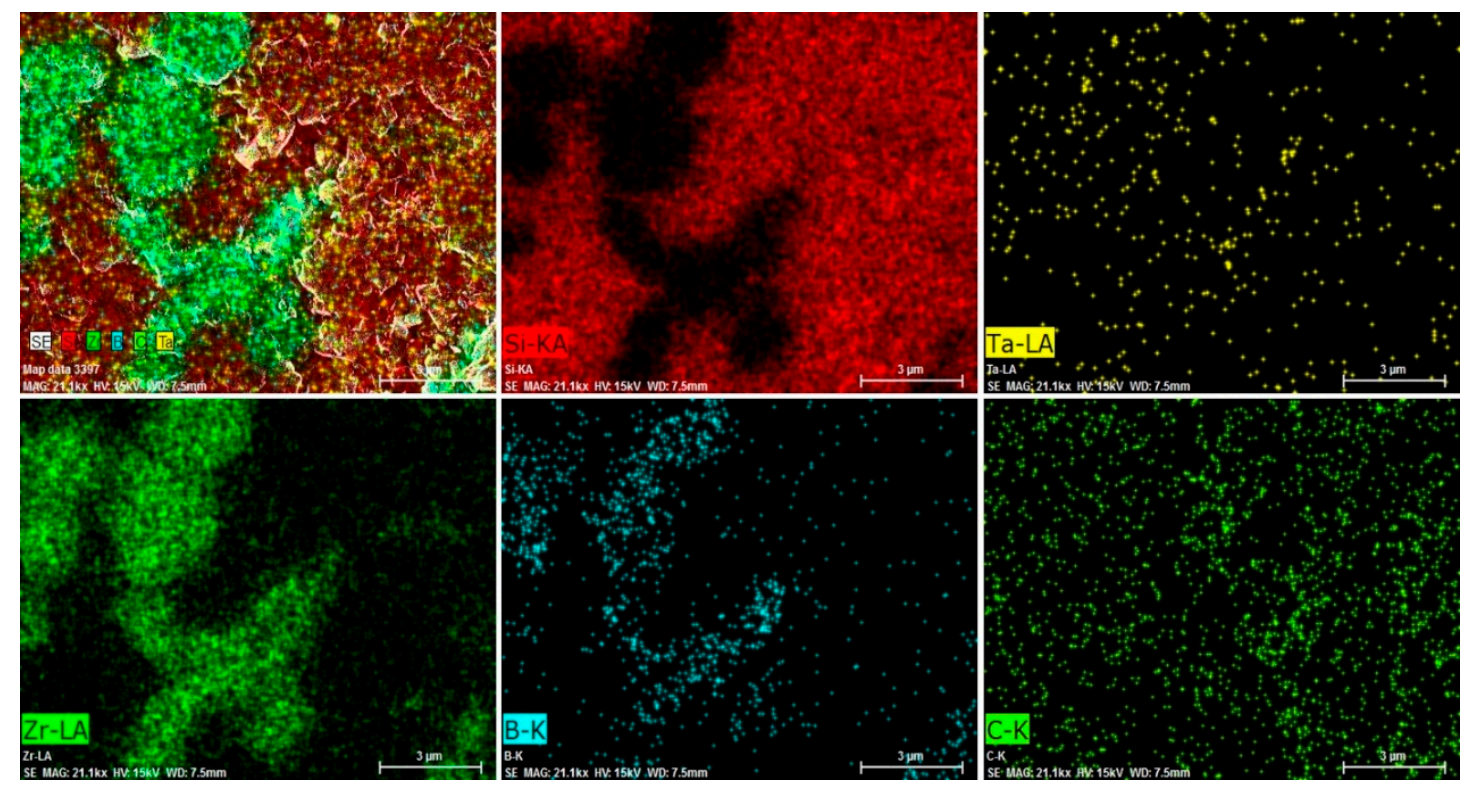

Figure 8. Energy-dispersive $\mathrm{X}$-ray spectroscopy (EDS) map of $\mathrm{ZrB}_{2}-\mathrm{SiC}-\mathrm{TaC}$. 
FE-EPMA was employed to explain and illustrate the carboniferous dopant existence in terms of primary graphite as well as recently-created zirconium diboride composite after sintering procedure (Figure 9).

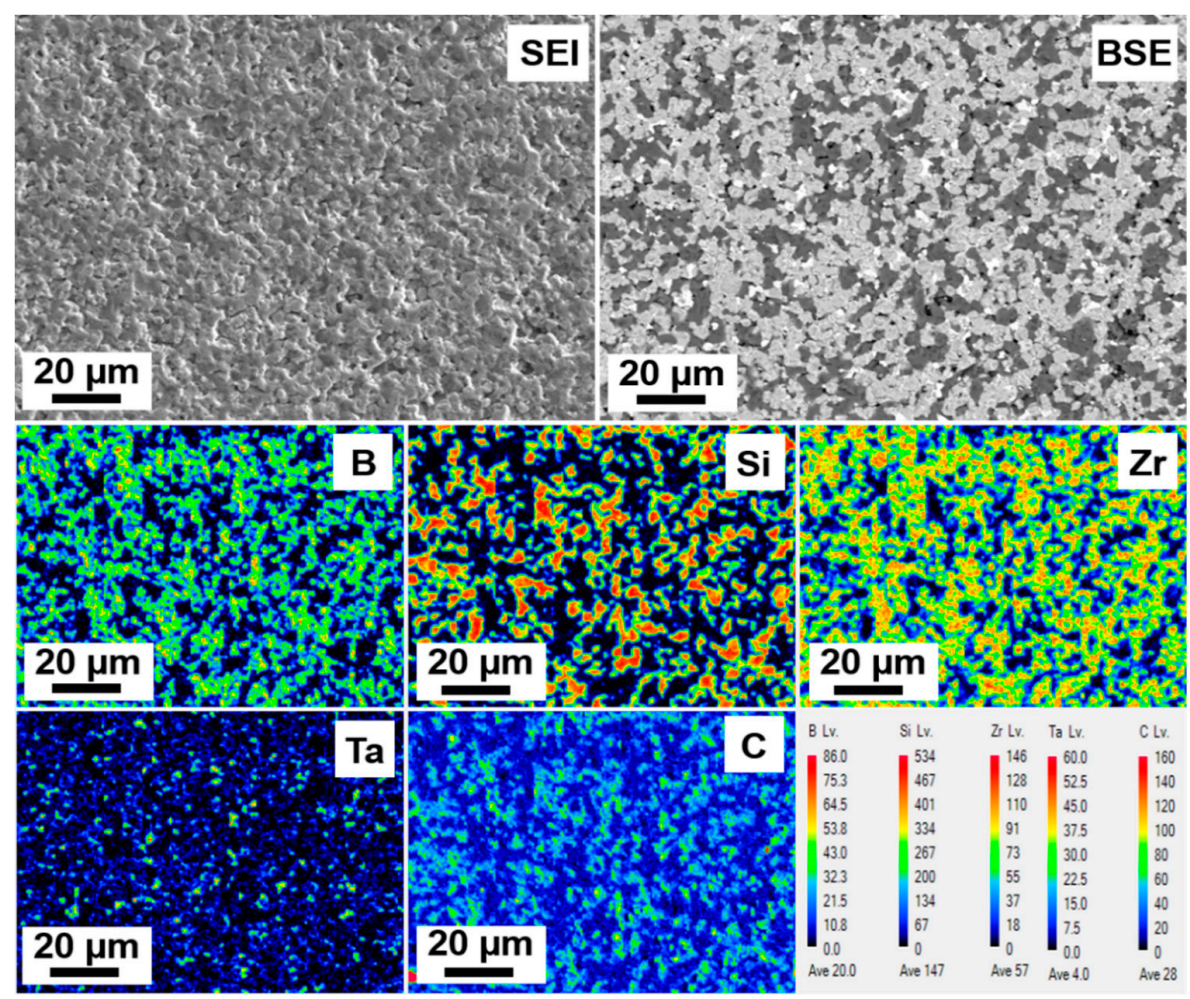

Figure 9. Field-emission-electron probe microanalysis (FE-EPMA) of $\mathrm{ZrB}_{2}-\mathrm{SiC}-\mathrm{TaC}$ and its constituent compounds.

\subsection{Computational Results}

To evaluate the applicability of the material of this study, we applied it to the leading edge of the aircraft wing and total body of the wing. The aim was to investigate the natural frequency of the wing by employing the finite element model (FEM) method through ABAQUS.

\subsubsection{Method Validity}

To evaluate the validity of the computational method of this study, the results given in the literature [50] dealing with the analysis of an aircraft wing was adopted to be compared with the current study. The example problem given in the aforementioned reference was modeled in this study. The Aluminum 2024-T3 was considered for the material of the wing and static analysis was performed to obtain the total deformation, equivalent stress, and equivalent strain. For the static analysis, the pressure force of $500 \mathrm{~Pa}$ was applied to the bottom surface of the wing at the center of the pressure. One end of the wing was completely constrained for all the degrees of freedom as it is embedded inside the fuselage while the other end was left free with six degrees of freedom. Thereafter, the results were compared with those of literature as provided in Table 3.

The last row of Table 3 shows the variation of the results of the current study and literature. The small amount of variation shows that the numerical model of this study could provide an acceptable prediction of the results and was in good agreement with literature. Therefore, the validity of the FEM analysis of the current study employing ABAQUS was approved. It can be adopted for further analysis to evaluate the natural frequencies of the aircraft wing considering the material produced in this study, $\mathrm{ZrB}_{2}-\mathrm{SiC}-\mathrm{TaC}$. 
Table 3. Comparison between the results of static analysis of aircraft wing obtained from the current study and literature [50].

\begin{tabular}{cccc}
\hline Entry & Total Deformation $(\mathbf{m m})$ & Equivalent Stress $\mathbf{( M P a )}$ & Equivalent Strain \\
\hline Reference [50] & 6.7377 & 16.034 & 0.00023 \\
Current & 6.8893 & 16.488 & 0.00075 \\
Variation\% & 2.25 & 2.75 & 2.26 \\
\hline
\end{tabular}

\subsubsection{The Natural Frequency of the Wing}

The illustrations of the first two modes of natural frequencies of wings are provided in Figure 10 for three cases: (i) $\mathrm{ZrB}_{2}-\mathrm{SiC}-\mathrm{TaC}$ as the leading edge and aluminum for the rest of the wing-body, (ii) $\mathrm{ZrB}_{2}-\mathrm{SiC}-\mathrm{TaC}$ used for all the body of wing, and (iii) aluminum used for the wing. As can be seen from Figure 10, the maximum displacement was observed at the free end of the wing. Similar mode shapes were obtained for the wings made of pure aluminum and $\mathrm{ZrB}_{2}-\mathrm{SiC}-\mathrm{TaC}$.
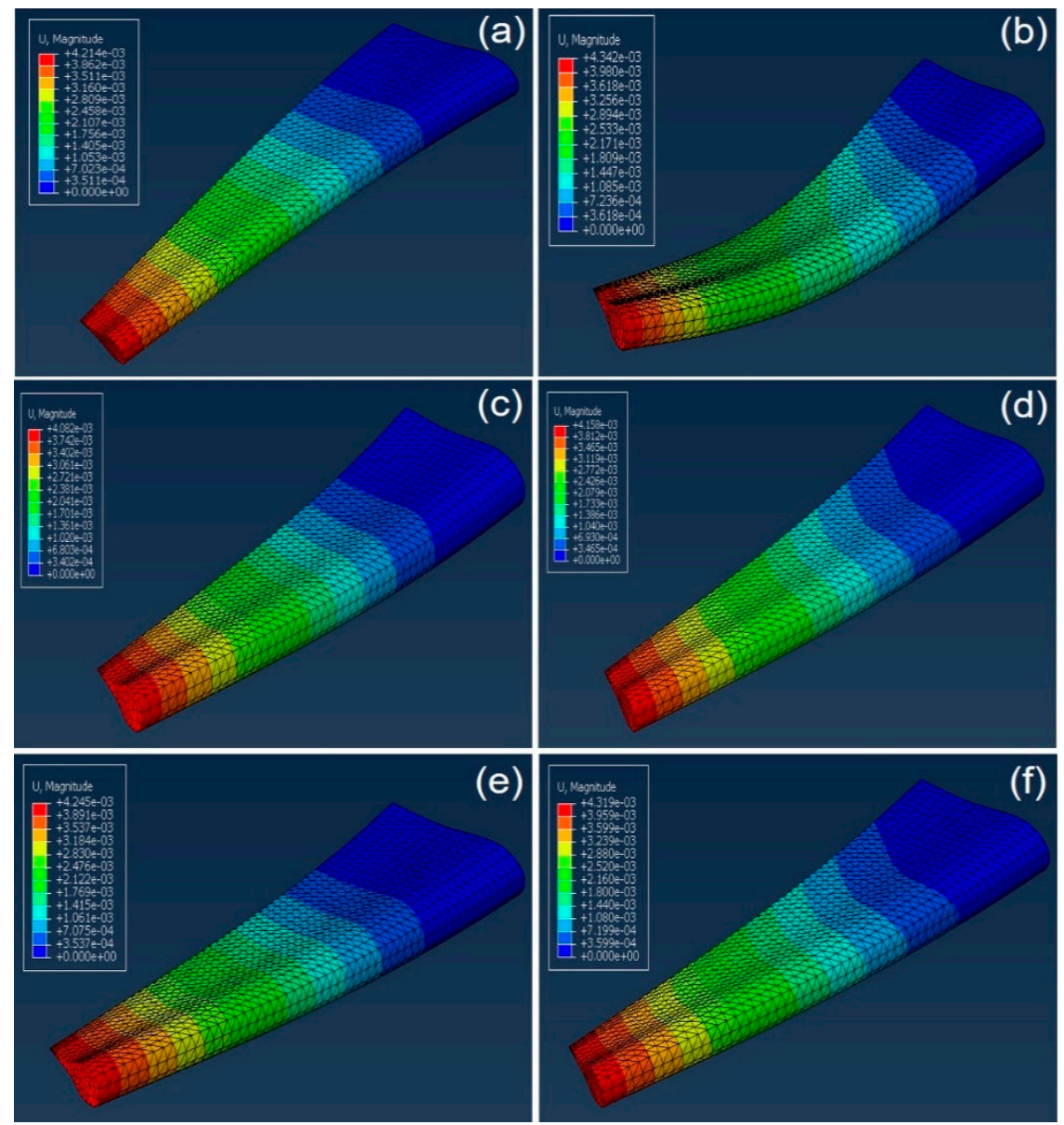

Figure 10. First two modes of wing natural frequency of (a) $\mathrm{ZrB}_{2}-\mathrm{SiC}-\mathrm{TaC}$ for the leading edge (model I), (b) $\mathrm{ZrB}_{2}-\mathrm{SiC}-\mathrm{TaC}$ for the leading edge (model II), (c) $\mathrm{ZrB}_{2}-\mathrm{SiC}-\mathrm{TaC}$ for the body of the wing (model I), (d) $\mathrm{ZrB}_{2}-\mathrm{SiC}-\mathrm{TaC}$ for the body of wing (model II), (e) aluminum for the body of wing (model I), and (f) aluminum for the body of wing (model II). 


\section{Discussions}

\subsection{Experiments}

Performing a set of experimental works resulted in the production of a refractory material called $\mathrm{ZrB}_{2}-\mathrm{SiC}-\mathrm{TaC}$ to provide superior thermal and mechanical properties for potential applications in structural, mechanical, aerospace, and biomedical areas. Thereafter, the composite was characterized by employing nano-indentation, XRD, XRF, and XPS. The densification of the material was completely achieved through the SPS process. Only peaks of zirconium and boron could be obtained allocated to the matrix of $\mathrm{ZrB}_{2}$. The peaks of silicon and carbon could be only detected as $\mathrm{SiC}$ additive. Figure 3 provides XRD of the $\mathrm{ZrB}_{2}-\mathrm{SiC}-\mathrm{TaC}$. Small values of the sedentary shaped $\mathrm{ZrB}_{2}$ phase enhanced the assumption indicating the bounded reaction between $\mathrm{TaC}$ and the face contamination of zirconium diboride-silicon carbide. Results revealed that the intensity of the $\mathrm{TaC}$ top point in the sintered compound was smaller than the powder admixture. The relative density of $\mathrm{ZrB}_{2}-\mathrm{SiC}-\mathrm{TaC}$ was $98.5 \%$ through the SPS process under the temperature of $2000^{\circ} \mathrm{C}$ and $30 \mathrm{MPa}$ pressure for $5 \mathrm{~min}$. Despite achieving the theoretical density for the composite of this study, the remaining $1.5 \%$ porosity in the as-sintered experimental sample could be attributed to insufficient sintering temperature or the absence of any metallic, carbonaceous, or other types of sintering aids. However, because of the negative effects of employing the sinter additives or higher sintering temperatures on the mechanical performance of sintered parts, a value of $98.5 \%$ would be admissible.

The XPS images of the composite and constituent compounds are provided in Figure 4. Having the XPS analysis of the materials, as a very advanced and accurate analysis tool, it was found that the purity of the composite is excellent, and no other compound was produced. Similar results were obtained by XRF analysis (Figure 5). Among the constituent materials, the highest intensity belonged to $\mathrm{ZrB}_{2}$ corresponding to the binding energy of approximately $178(\mathrm{eV})$. The lowest intensity attributed to $\mathrm{TaC}$ with a magnitude of 2300 which occurred on the binding energy equal to $23(\mathrm{eV})$.

It has been documented that there is a possibility of the creation of new compounds as well as the desired main composite during the manufacturing process. For example, Ghassemi Kakroudi and co-workers [38] detected two other compounds including $\mathrm{ZrC}$ and $\mathrm{TaSi}_{2}$ during the hot process manufacturing of $\mathrm{ZrB}_{2}-\mathrm{SiC}-\mathrm{TaC}$. They explained that it could be because of the formation of oxide impurity on the surface of $\mathrm{ZrB}_{2}$ powders as the main component of the mixture. They suggested the chemical reaction formula given in Equation (1) for the verification of this outcome [38]:

$$
2 \mathrm{SiC}+\mathrm{TaC}+\mathrm{ZrO}_{2} \rightarrow \mathrm{TaSi}_{2}+\mathrm{ZrC}+2 \mathrm{CO}
$$

However, from the outcomes obtained from XRD, XPS analysis of the current study, no extra in situ formation of new compounds was observed except the main composite of desire. This superior result was achieved due to employing the advanced SPS manufacturing process which is preferable to the other existent manufacturing processes.

Figure 6 shows the load-displacement relation of the material obtained from the nano-indentation technique. As can be seen, the result was achieved through five loading-unloading processes. After each cycle, the amount of displacement increased with respect to the same loading amounts which shows the slight reduction in the rigidity of the material. By using the nano-indentation graphs, the characteristics of the composite of this study were attained. The mechanical and thermal characteristics of the composite and $\mathrm{ZrB}_{2}-\mathrm{SiC}-\mathrm{TaC}$ interface are given in Table 2 shows a substantial reduction in the minimum and mean rigidity and modulus of elasticity of the interface with respect to those of zirconium diboride, silicon carbide, and tantalum carbide phases. It was observed that the existence of residual porosities and oxides could result in a decrease in rigidity and modulus of elasticity at the interface. It was found that $\mathrm{SiC}$ dominated in the regarding indent because of the indentation head position. For example, the case can be considered as the principal segment of the projected region positioned within silicon carbide for which the force-displacement relation tended to that of 
$\mathrm{SiC}$. By contrast, when the indentation was positioned within the $\mathrm{ZrB}_{2}$ phase, the properties of the force-displacement relationship tended to $\mathrm{ZrB}_{2}$. The same pattern was also observed for the TaC for which the material characteristics presented those of $\mathrm{TaC}$ when the indentation placed within $\mathrm{TaC}$.

FESEM images of the surface of the composite are shown in Figure 7 comprising grey, dark, and bright areas correspondence to $\mathrm{ZrB}_{2}, \mathrm{SiC}$, and TaC grains, respectively. There is a good consistency with the volume ratios of each phase in the powder mixture. Besides, this microstructural result was in good agreement with the relative density value of $98.5 \%$ for the sintered bulk. EDS of the composite also confirms the integrity and presence of the constituent elements in the $\mathrm{ZrB}_{2}-\mathrm{SiC}-\mathrm{TaC}$ (Figure 8). The FE-EPMA map also shows the areal information on the properties of the composite and its chemical components provided in Figure 9. These results demonstrated the distribution map of each component and the whole composition of $\mathrm{ZrB}_{2}-\mathrm{SiC}-\mathrm{TaC}$.

\subsection{Finite Element Method}

The numerical analysis of the aircraft wing was performed to investigate the effect of the application of $\mathrm{ZrB}_{2}-\mathrm{SiC}-\mathrm{TaC}$ on the natural frequency of the aircraft wing. The first two shape modes of the wings corresponding to different cases from the viewpoint of the material are provided in Figure 10. As can be seen from Figure 10, the free end of the wing sustained the highest displacement. To provide a better understanding of the efficiency of the material of this study, the amounts of natural frequencies corresponding to the first three mode shapes, the most important modes, are provided and compared in Table 4.

Table 4. First three modes corresponding to the aircraft wing natural frequencies.

\begin{tabular}{cccc}
\hline Material & Mode I (Cycle/Time) & Mode II (Cycle/Time) & Mode III (Cycle/Time) \\
\hline $\mathrm{ZrB}_{2}-\mathrm{SiC}-\mathrm{Tac}$ & $2.67 \times 10^{-3}$ & $1.13 \times 10^{-2}$ & $1.14 \times 10^{-2}$ \\
$\mathrm{Al}$ & $2.56 \times 10^{-3}$ & $9.91 \times 10^{-3}$ & $1.08 \times 10^{-2}$ \\
$\mathrm{ZrB}_{2}-\mathrm{SiC}-\mathrm{Tac}+\mathrm{Al}$ & $5.79 \times 10^{-3}$ & $2.24 \times 10^{-2}$ & $2.44 \times 10^{-2}$ \\
Variation $\%(\mathrm{Al} / \mathrm{Zr})$ & 4.12 & 12.30 & 5.26 \\
Variation\% $(\mathrm{Al} / \mathrm{Zr}-\mathrm{Al})$ & 55.79 & 55.76 & 55.74 \\
\hline
\end{tabular}

According to the results given in Table 4, the natural frequency of the aircraft wing is changed by using $\mathrm{ZrB}_{2}-\mathrm{SiC}-\mathrm{TaC}$. It was observed that employing the material of this study for the leading edge of the wing increased the natural frequency by over $50 \%$. Moreover, it was seen that having used the presented composite instead of aluminum for the wing resulted in a small increase in natural frequencies. Using the composite of this study significantly enhances the stiffness of the wing as well as its thermal resistance.

\section{Conclusions}

This presented a new type of ultra-high temperature ceramic, $\mathrm{ZrB}_{2}-\mathrm{SiC}-\mathrm{TaC}$, having the thermal resistance beyond $3000{ }^{\circ} \mathrm{C}$, and superior mechanical properties. The purpose of the study was to produce new material for structural and aerospace applications. The designed composite was produced by combining zirconium diboride, silicon carbide, and tantalum carbide sintered by spark plasma sintering. This new composite was characterized through the nano-indentation, $\mathrm{X}$-ray diffractometer, $\mathrm{X}$-ray fluorescence spectrometer, field emission-electron probe microanalyzer, and field-emission scanning electron microscopy. This composite possesses a melting point beyond $3000{ }^{\circ} \mathrm{C}$, elastic modulus, and rigidity. Its possible application in aerospace was illustrated. To depict the workability and applicability of the material of this study, the computational method was adopted to model the aircraft wing through finite element model analysis employing ABAQUS. In this regard, three cases were considered from the viewpoint of specifying $\mathrm{ZrB}_{2}-\mathrm{SiC}-\mathrm{TaC}$ in the wing: i) only applied to the leading edge of the wing, ii) considered for the wing as a whole, and iii) only aluminum 2024-T3 applied to the wing without consideration of $\mathrm{ZrB}_{2}-\mathrm{SiC}-\mathrm{TaC}$. Comparison studies between the results showed 
that employing $\mathrm{ZrB}_{2}-\mathrm{SiC}-\mathrm{TaC}$ enhances the structural performance of the wing and changes its natural frequency substantially when it is considered as a leading edge of the wing. When $\mathrm{ZrB}_{2}-\mathrm{SiC}-\mathrm{TaC}$ was applied to the wing as a whole, a small variation was observed with the case of wing fully made of aluminum 2024-T3. It can be concluded that the best case is to apply this composite for the leading edge of the wing.

Author Contributions: Conceptualization, B.M.; J.K. and M.S.; methodology, B.M. and M.S.; software, B.M. and J.K.; validation, B.M.; J.K.; Q.V.L.; S.-H.L. and M.S.; formal analysis, B.M. and M.S.; investigation, B.M.; S.J.; T.H.L.; J.H.C.; H.W.J.; and M.S.; resources, B.M.; S.J.; T.H.L.; J.H.C.; H.W.J.; and M.S.; data curation, B.M.; S.J.; T.H.L.; and M.S.; writing—original draft preparation, B.M.; S.J.; T.H.L. and M.S.; writing-review and editing, B.M.; J.K. and M.S.; visualization, B.M.; S.J.; T.H.L. and M.S.; supervision, J.K.; Q.V.L.; S.-H.L.; project administration, S.J.; T.H.L. and M.S.; funding acquisition, J.K.; Q.V.L.; S.-H.L., and M.S. All authors have read and agreed to the published version of the manuscript.

Funding: This work was funded by the grant (19CTAP-C144787-02) of the Ministry of Land, Infrastructure, and Transport (MOLIT) of the Korean Agency for Infrastructure Technology Advancement (KAIA). In addition, the financial supports of Future Material Discovery Program (2016M3D1A1027666), and the Basic Science Research Program (2017R1A2B3009135) through the National Research Foundation of Korea.

Conflicts of Interest: The authors declare no conflict of interest. The funders had no role in the design of the study; in the collection, analyses, or interpretation of data; in the writing of the manuscript, or in the decision to publish the results.

\section{References}

1. Fahrenholtz, W.G.; Hilmas, G.E.; Chamberlain, A.L.; Zimmermann, J.W. Processing and characterization of $\mathrm{ZrB}_{2}$-based ultra-high temperature monolithic and fibrous monolithic ceramics. J. Mater. Sci. 2004, 39, 5951-5957. [CrossRef]

2. Dai, F.; Zhou, Y. Reducing the ideal shear strengths of $\mathrm{ZrB}_{2}$ by high efficient alloying elements $(\mathrm{Ag}, \mathrm{Au}, \mathrm{Pd}$ and Pt). Sci. Rep. 2017, 7, 43416. [CrossRef] [PubMed]

3. Shahedi Asl, M.; Nayebi, B.; Ahmadi, Z.; Parvizi, S.; Shokouhimehr, M. A novel ZrB ${ }_{2}-\mathrm{VB}_{2}-\mathrm{ZrC}$ composite fabricated by reactive spark plasma sintering. Mater. Sci. Eng. A 2018, 731, 131-139. [CrossRef]

4. Feng, X.; Wang, X.; Liu, Y.; Guo, Y.; Zhang, M.; Zhang, L.; Jian, X.; Yin, L.; Xie, J.; Deng., L. Oxidation behaviour of plasma-sprayed $\mathrm{ZrB}_{2}$-SiC coatings. Ceram. Int. 2019, 45, 2385-2392. [CrossRef]

5. Zoli, L.; Vinci, A.; Galizia, P.; Melandri, C.; Sciti, D. On the thermal shock resistance and mechanical properties of novel unidirectional UHTCMCs for extreme environments. Sci. Rep. 2018, 8, 9148. [CrossRef] [PubMed]

6. Oliveros, A.; Coletti, C.; Saddow, S.E. Carbon based materials on SiC for advanced biomedical applications. In Silicon Carbide Biotechnology; Elsevier: Waltham, MA, USA, 2012; Volume 12, pp. 431-458. [CrossRef]

7. Guo, S.Q. Densification of $\mathrm{ZrB}_{2}$-based composites and their mechanical and physical properties: A review. J. Eur. Ceram. Soc. 2009, 29, 995-1011. [CrossRef]

8. Wuchina, E.; Opila, E.; Opeka, M.; Fahrenholtz, W.; Talmy, I. UHTCs: Ultra-high temperature ceramic materials for extreme environment applications. Electrochem. Soc. Interface 2007, 16, 30.

9. Cedillos-Barraza, O.; Manara, D.; Boboridis, K.; Watkins, T.; Grasso, S.; Jayaseelan, D.D.; Konings, R.J.; Reece, M.J.; Lee, W.E. Investigating the highest melting temperature materials. A laser melting study of the TaC-HfC system. Sci. Rep. 2016, 6, 37962. [CrossRef]

10. Silvestroni, L.; Kleebe, H.; Fahrenholtz, W.; Watts, J. Super-strong materials for temperatures exceeding $2000^{\circ}$ C. Sci. Rep. 2017, 7, 40730. [CrossRef]

11. Zhang, G.J.; Guo, W.M.; Ni, D.W.; Kan, Y.M. Ultrahigh temperature ceramics (UHTCs) based on ZrB 2 and $\mathrm{HfB}_{2}$ systems: Powder synthesis, densification and mechanical properties. J. Phys. Conf. Ser. 2009, 176, 012041. [CrossRef]

12. Nisbet, H.; Migdisov, A.A.; Williams-Jones, A.E.; Xu, H.; van Hinsberg, V.J.; Roback, R. Challenging the thorium-immobility paradigm. Sci. Rep. 2019, 9, 17035. [CrossRef] [PubMed]

13. Jiang, M.; Zheng, J.W.; Xiao, H.Y.; Liu, Z.J.; Zu, X.T. A comparative study of the mechanical and thermal properties of defective $\mathrm{ZrC}, \mathrm{TiC}$ and SiC. Sci. Rep. 2017, 7, 9344. [CrossRef] [PubMed]

14. Smith, C.J.; Ross, M.A.; Leon, N.D.; Weinberger, C.R.; Thompson, G.B. Ultra-high temperature deformation in TaC and HfC. J. Eur. Ceram. 2018, 38, 5319-5332. [CrossRef] 
15. Lawson, J.W.; Murray, S.D.; Charles, W. Bauschlicher. Lattice thermal conductivity of ultra high temperature ceramics $\mathrm{ZrB}_{2}$ and $\mathrm{HfB}_{2}$ from atomistic simulations. J. Appl. Phys. 2011, 110, 083507. [CrossRef]

16. Ma, H.B.; Man, Z.Y.; Liu, J.X.; Xu, F.F.; Zhang, G.J. Microstructures, solid solution formation and high-temperature mechanical properties of $\mathrm{ZrB}_{2}$ ceramics doped with 5 vol.\% WC. Mater. Des. 2015, 81, 133-140. [CrossRef]

17. Guo, W.M.; Zhang, G.J. Reaction processes and characterization of $\mathrm{ZrB}_{2}$ powder prepared by boro/carbothermal reduction of $\mathrm{ZrO}_{2}$ in vacuum. J. Am. Ceram. Soc. 2009, 92, 264-267. [CrossRef]

18. Hu, P.; Wang, Z. Flexural strength and fracture behavior of $\mathrm{ZrB}_{2}-\mathrm{SiC}$ ultra-high temperature ceramic composites at $1800^{\circ} \mathrm{C}$. J. Eur. Ceram. Soc. 2010, 30, 1021-1026. [CrossRef]

19. Shen, Y.; Jiang, J.C.; Zeman, P.; Šímová, V.; Vlček, J.; Meletis, E.I. Microstructure evolution in amorphous Hf-B-Si-C-N high temperature resistant coatings after annealing to $1500{ }^{\circ} \mathrm{C}$ in air. Sci. Rep. 2019, 9, 3603. [CrossRef]

20. Šímová, V.; Vlček, J.; Zuzjaková, Š.; Houška, J.; Shen, Y.; Jiang, J.; Meletis, E.I.; Peřina, V. Magnetron sputtered Hf-B-Si-C-N films with controlled electrical conductivity and optical transparency, and with ultrahigh oxidation resistance. Thin Solid Film. 2018, 653, 333-340. [CrossRef]

21. Gild, J.; Zhang, Y.; Harrington, T.; Jiang, S.; Hu, T.; Quinn, M.C.; Mellor, W.M.; Zhou, N.; Vecchio, K.; Luo, J. High-entropy metal diborides: A new class of high-entropy materials and a new type of ultrahigh temperature ceramics. Sci. Rep. 2016, 6, 37946. [CrossRef]

22. Wu, P.; Lv, H.; Peng, T.; He, D.; Mu, S. Nano conductive ceramic wedged graphene composites as highly efficient metal supports for oxygen reduction. Sci. Rep. 2015, 4, 3968. [CrossRef] [PubMed]

23. Zapata-Solvas, E.; Jayaseelan, D.D.; Lin, H.T.; Brown, P.; Lee, W.E. Mechanical properties of ZrB ${ }_{2}-$ and $\mathrm{HfB}_{2}$-based ultra-high temperature ceramics fabricated by spark plasma sintering. J. Eur. Ceram. 2013, 33, 1373-1386. [CrossRef]

24. Tan, W.; Petorak, C.A.; Trice, R.W. Rare-earth modified zirconium diboride high emissivity coatings for hypersonic applications. J. Eur. Ceram. Soc. 2014, 34, 1-11. [CrossRef]

25. Neuman, E.W.; Hilmas, G.E.; Fahrenholtz, W.G. Mechanical behavior of zirconium diboride-silicon carbide ceramics at elevated temperature in air. J. Eur. Ceram. Soc. 2013, 33, 2889-2899. [CrossRef]

26. Neuman, E.W.; Hilmas, G.E.; Fahrenholtz, W.G. Mechanical behavior of zirconium diboride-silicon carbide-boron carbide ceramics up to $2200^{\circ} \mathrm{C}$. J. Eur. Ceram. Soc. 2015, 35, 463-476. [CrossRef]

27. D'Angio, A.; Zou, J.; Binner, J.; Ma, H.B.; Hilmas, G.E.; Fahrenholtz, W.G. Mechanical properties and grain orientation evolution of zirconium diboride-zirconium carbide ceramics. J. Eur. Ceram. Soc. 2018, 38, 391-402. [CrossRef]

28. Silvestroni, L.; Mungiguerra, S.; Sciti, D.; Martino, G.D.D.; Savino, R. Effect of hypersonic flow chemical composition on the oxidation behavior of a super-strong UHTC. Corros. Sci. 2019, 159, 108125. [CrossRef]

29. Shahedi Asl, M.; Nayebi, B.; Ahmadi, Z.; Jaberi Zamharir, M.; Shokouhimehr, M. Effects of carbon additives on the properties of $\mathrm{ZrB}_{2}$-based composites: A review. Ceram. Int. 2018, 44, 7334-7348. [CrossRef]

30. An, Y.; Han, W.; Han, J.; Zhao, G.; Zhou, S.; Zhang, X. Synergistic effect on the mechanical behaviors of ternary graphene oxide-zirconium diboride-poly(vinyl alcohol) papers. Mater. Des. 2016, 112, 275-281. [CrossRef]

31. Sonber, J.K.; Raju, K.; Murthy, T.C.R.C.; Sairam, K.; Nagaraj, A.; Majumdar, S.; Kain, V. Friction and wear properties of zirconium diboride in sliding against WC ball. Int. J. Refract. Met. Hard Mater. 2018, 76, 41-48. [CrossRef]

32. Shahedi Asl, M.; Nayebi, B.; Shokouhimehr, M. TEM characterization of spark plasma sintered $\mathrm{ZrB}_{2}-\mathrm{SiC}$-graphene nanocomposite. Ceram. Int. 2018, 44, 15269-15273. [CrossRef]

33. Nayebi, B.; Ahmadi, Z.; Shahedi Asl, M.; Parvizi, S.; Shokouhimehr, M. Influence of vanadium content on the characteristics of spark plasma sintered $\mathrm{ZrB}_{2}-\mathrm{SiC}-\mathrm{V}$ composites. J. Alloys Compd. 2019, 805, 725-732. [CrossRef]

34. Chakraborty, S.; Das, P.K.; Ghosh, D. Spark plasma sintering and structural properties of Z Zrb 2 based ceramics: A review. Rev. Adv. Mater. Sci. 2016, 44, 182-193.

35. Zhang, X.; An, Y.; Han, J.; Han, W.; Zhao, G.; Jin, X. Graphene nanosheet reinforced $\mathrm{ZrB}_{2}-\mathrm{SiC}$ ceramic composite by thermal reduction of graphene oxide. RSC Adv. 2016, 5, 47060-47065. [CrossRef]

36. Thimmappa, S.K.; Golla, B.R.; Prasad, V.V.B.; Majumdar, B.; Basu, B. Phase stability, hardness and oxidation behavior of spark plasma sintered $\mathrm{ZrB}_{2}-\mathrm{SiC}_{-} \mathrm{Si}_{3} \mathrm{~N}_{4}$ composites. Ceram. Int. 2019, 45, 9061-9073. [CrossRef] 
37. Sha, J.J.; Li, J.; Lv, Z.Z.; Wang, S.H.; Zhang, Z.F.; Zu, Y.F.; Flauder, S.; Krenkel, W. ZrB 2 -based composites toughened by as-received and heat-treated short carbon fibers. J. Eur. Ceram. Soc. 2017, 37, 549-558. [CrossRef]

38. Ghassemi Kakroudi, M.; Dehghanzadeh Alvari, M.; Shahedi Asl, M.; Pourmohammadie Vafa, N.; Rabizadeh, T. Hot pressing and oxidation behavior of $\mathrm{ZrB}_{2}-\mathrm{SiC}-\mathrm{TaC}$ composites. Ceram. Int. 2020, 46, 3725-3730. [CrossRef]

39. Sharifianjazi, F.; Pakseresht, A.H.; Shahedi Asl, M.; Esmaeilkhanian, A.; Nargesi Khoramabadi, H.; Jang, H.W.; Shokouhimehr, M. Hydroxyapatite consolidated by zirconia: Applications for dental implant. J. Compos. Compd. 2020, 2, 26-34. [CrossRef]

40. Rafiaei, S.M.; Bahrami, A.; Shokouhimehr, M. Influence of $\mathrm{Ni} / \mathrm{Co}$ binders and $\mathrm{Mo}_{2} \mathrm{C}$ on the microstructure evolution and mechanical properties of $\left(\mathrm{Ti}_{0.93} \mathrm{~W}_{0.07}\right)$ C-based Cermets. Ceram. Int. 2018, 44, 17655-17659. [CrossRef]

41. Maleki, M.; Beitollahi, A.; Shokouhimehr, M. Template-free synthesis of porous boron nitride using a single source precursor. RSC Adv. 2015, 5, 6528-6535. [CrossRef]

42. Vajdi, M.; Sadegh Moghanlou, F.; Sharifianjazi, F.; Shahedi Asl, M.; Shokouhimehr, M. A review on the COMSOL Multiphysics studies of heat transfer in advanced ceramics. J. Compos. Compd. 2020, 2, 35-44. [CrossRef]

43. Ahmadi, Z.; Nayebi, B.; Parvizi, S.; Shahedi Asl, M.; Shokouhimehr, M. Phase transformation in spark plasma sintered $\mathrm{ZrB}_{2}-\mathrm{V}-\mathrm{C}$ composites at different temperatures. Ceram. Int. 2020, 46, 9415-9420. [CrossRef]

44. Shokouhimehr, M.; Mahmoudi Gom-Yek, S.; Nasrollahzadeh, M.; Kim, A.; Varma, R.S. Palladium nanocatalysts on hydroxyapatite: Green oxidation of alcohols and reduction of nitroarenes in water. Appl. Sci. 2019, 9, 4183. [CrossRef]

45. Vajdi, M.; Sadegh Moghanlou, F.; Ranjbarpour Niari, E.; Shahedi Asl, M.; Shokouhimehr, M. Heat transfer and pressure drop in a $\mathrm{ZrB}_{2}$ microchannel heat sink: A numerical approach. Ceram. Int. 2020, 46, 1730-1735. [CrossRef]

46. Shahedi Asl, M.; Nayebi, B.; Ghassemi Kakroudi, M.; Shokouhimehr, M. Investigation of hot pressed $\mathrm{ZrB}_{2}-\mathrm{SiC}$-carbon black composite by scanning and transmission electron microscopy. Ceram. Int. 2019, 45, 16759-16764. [CrossRef]

47. Ramezanalizadeh, H.; Emamy, M.; Shokouhimehr, M. Wear behavior of Al/CMA-type $\mathrm{Al}_{3} \mathrm{Mg}_{2} \mathrm{Nanocomposites}$ fabricated by mechanical milling and hot extrusion. Tribol. Trans. 2016, 59, 219-228. [CrossRef]

48. Nayebi, B.; Shahedi Asl, M.; Ghassemi Karoudi, M.; Shokouhimehr, M. Temperature dependence of microstructure evolution during hot pressing of $\mathrm{ZrB}_{2}-30$ vol\% SiC composites. Ceram. Int. 2016, 54, 7-13. [CrossRef]

49. Nayebi, B.; Shahedi Asl, M.; Ghassemi Kakroudi, M.; Farahbakhsh, I.; Shokouhimehr, M. Interfacial phenomena and formation of nano-particles in porous $\mathrm{ZrB}_{2}-40$ vol\% B4C UHTC. Ceram. Int. 2016, 42, 17009-17015. [CrossRef]

50. Das, S.K.; Roy, S. Finite element analysis of aircraft wing using carbon fiber reinforced polymer and glass fiber reinforced polymer. IOP Conf. Ser. Mater. Sci. Eng. 2018, 402, 012077. [CrossRef]

51. Mohammadzadeh, B.; Choi, E.; Kim, D. Vibration of sandwich plates considering elastic foundation, temperature change and FGM faces. Struct. Eng. Mech. 2019, 70, 601-621. [CrossRef]

52. Mohammadzadeh, B.; Noh, H.C. Analytical method to investigate nonlinear dynamic responses of sandwich plates with FGM faces resting on elastic foundation considering blast loads. Compos. Struct. 2017, 174, 142-157. [CrossRef]

53. Mohammadzadeh, B.; Noh, H.C. Numerical analysis of dynamic responses of the plate subjected to impulsive loads. Int. J. Civ. Environ. Struct. Constr. Archit. Eng. 2015, 9, 1148-1151.

54. Mohammadzadeh, B.; Noh, H.C. An analytical and numerical investigations on the dynamic responses of steel plates considering the blast loads. Int. J. Steel Struct. 2018, 19, 603-617. [CrossRef]

55. Mohammadzadeh, B.; Noh, H.C. Investigation into central-difference and Newmark's beta method in measuring dynamic responses. Adv. Mater. Res. 2014, 831, 95-99. [CrossRef]

56. Mohammadzadeh, B.; Bina, M.; Hasounizadeh, H. Application and comparison of mathematical and physical models on inspecting slab of stilling basin floor under static and dynamic forces. Appl. Mech. Mater. 2012, 147, 283-287. [CrossRef]

57. Mohammadzadeh, B.; Noh, H.C. Investigation into buckling coefficients of plates with holes considering variation of hole size and plate thickness. Mechanika 2016, 22, 167-175. [CrossRef] 
58. Mohammadzadeh, B.; Noh, H.C. Use of buckling coefficient in predicting buckling load of plates with and without holes. J. Korean Soc. Adv. Compos. Struct. 2014, 5, 1-7. [CrossRef]

59. Mohammadzadeh, B.; Choi, E.; Kim, W.J. Comprehensive investigation of buckling behavior of plates considering effects of holes. Struct. Eng. Mech. 2018, 68, 261-275. [CrossRef]

60. Whally, R.; Ebrahimi, M. Vibration and control of aircraft wings. Proc. Inst. Mech. Eng. Part G J. Aerosp. Eng. 1998, 212, 353-365. [CrossRef]

(C) 2020 by the authors. Licensee MDPI, Basel, Switzerland. This article is an open access article distributed under the terms and conditions of the Creative Commons Attribution (CC BY) license (http://creativecommons.org/licenses/by/4.0/). 